\title{
Social media for physiotherapy clinics: considerations in creating a Facebook page
}

\author{
Osman H. Ahmed ${ }^{1}$, Leica S. Claydon', Daniel C. Ribeiro ${ }^{1,2}$, Ashokan Arumugam¹, \\ Chris Higgs ${ }^{1}$, G. David Baxter ${ }^{1}$
}

${ }^{1}$ School of Physiotherapy, University of Otago, Dunedin, New Zealand, ${ }^{2}$ Otago Institute of Sport and Adventure, Otago Polytechnic, Dunedin, New Zealand

\begin{abstract}
Social media websites play a prominent role in modern society, and the most popular of these websites is Facebook. Increasingly, physiotherapy clinics have begun to utilize Facebook in order to create pages to publicize their services. There are many factors to consider in the planning, implementing, and maintenance of Facebook pages for physiotherapy clinics, including ethical and privacy issues. The primary purpose of creating a page must be clearly defined, with dedicated clinicians given adequate time to manage the page. This technical article discusses these factors and summarizes the experiences at the University of Otago, New Zealand, in creating a Facebook page for the physiotherapy clinic and provides suggestions for physiotherapy clinicians in operating a Facebook page.
\end{abstract}

Keywords: Internet, Social networking sites, Health promotion, Physiotherapy, Professional practice

\section{Introduction}

Social media ('websites and applications used for social networking, ${ }^{1}$ ) are a growing influence in modern society. The largest social media applications such as Facebook, Twitter, and YouTube are among the most widely-used of all websites, ${ }^{2}$ with Facebook alone having over 800 million active users. ${ }^{3}$ Each of these social media websites have varying functionality and capability, and enable users to interact in different ways (Table 1).

Facebook was created in 2004, initially to enable students at Harvard University to connect with other students within the University. Its popularity soon spread to other universities across America, and then to high schools, and eventually to a global audience. ${ }^{4}$ Facebook allows users to create an online profile, upload photos and videos, exchange messages with other users, and post information on other users' profiles (called 'walls'). It also permits users to join groups on all manner of topics, including for healthrelated purposes, ${ }^{5}$ and to 'like' information on other people's profiles (Fig. 1).

Twitter is a micro blogging service which enables a rapid exchange of information. ${ }^{6}$ Users send 140character messages (called 'tweets') which are received by other users they are linked to ('followers'); users can also send other members direct

Correspondence to: O Ahmed, Centre for Physiotherapy Research, University of Otago, PO Box 56, Dunedin 9054, New Zealand. Email: osman.ahmed@otago.ac.nz messages (Fig. 2). ${ }^{7}$ Twitter currently has over 200 million user accounts, with $25 \%$ of those users logging in daily. ${ }^{6}$ Recent research has demonstrated examples of the use of Twitter in healthcare for a wide variety of purposes, including to improve quality of life, ${ }^{8}$ share information about symptoms, ${ }^{9}$ spread awareness of illnesses, ${ }^{10}$ and to discuss medications. $^{11}$

YouTube is dedicated to video-sharing, and members can upload, watch, and share videos with a global audience (Fig. 3). Since its inception in 2005, YouTube has grown to such an extent that it exceeds two billion views every day, ${ }^{12}$ and is the third most accessed website in the world. ${ }^{13}$ Individuals, companies, and institutions upload videos on all manner of topics, for entertainment or for educational purposes. There is a huge quantity of health information present on YouTube, and recently there has been an increase in the examples of health-related research being conducted on this social networking site. ${ }^{14,15}$

The field of healthcare has been party to this shift towards social media, and many medical organisations have Facebook pages, Twitter feeds, or YouTube accounts. In the UK, NHS Direct has over 10000 Twitter followers ${ }^{16}$ and a Facebook page, ${ }^{17}$ while the Mayo Clinic in the USA has a YouTube channel with nearly 1,500 videos. ${ }^{18}$ A recent report supports this strategy, suggesting that healthcare users consider the social media presence of a hospital when choosing where to seek treatment. ${ }^{19}$ 
Table 1 Comparison of Facebook, Twitter, and YouTube

\begin{tabular}{|c|c|c|c|}
\hline & Facebook & Twitter & YouTube \\
\hline URL & http://www.facebook.com & http://www.twitter.com & http://www.youtube.com \\
\hline Date launched & February 2004 & July 2006 & February 2005 \\
\hline Key feature & $\begin{array}{l}\text { Creating an online profile to } \\
\text { interact with other users }\end{array}$ & $\begin{array}{l}\text { Sending messages of } 140 \\
\text { characters for rapid exchange } \\
\text { of information }\end{array}$ & $\begin{array}{l}\text { Uploading, sharing and } \\
\text { watching videos online }\end{array}$ \\
\hline Usage & Over 800 million members ${ }^{3}$ & Over 200 million members ${ }^{6}$ & Over 2 billion videos viewed per day ${ }^{12}$ \\
\hline
\end{tabular}

The physiotherapy profession has not been exempt from these developments, and the potential for physiotherapists to engage in social media is apparent. ${ }^{20}$ Giordano and Giordeno included physical therapy students in a survey of social media use among health professions students, ${ }^{21}$ and reported that $77 \%$ of all students sampled had a Facebook account. Benefits of social media for physiotherapists include the facilitation of learning, enabling professional networking, aiding contributions towards the research base, and as a promotional tool. ${ }^{22}$ Physiotherapists are currently using social networking sites for discussion forums, collaborating with overseas colleagues, and also for job advice (one such Facebook group, 'Interview questions for junior physios', currently has almost 4500 members $^{23}$ ). Hundreds of physiotherapy clinics have established Facebook pages, and a brief search of physiotherapy clinics listed on Facebook shows that this is a global phenomenon.

Given the popularity of Facebook, it is the logical choice for many physiotherapy clinics (and other clinical services and departments) who wish to promote their services. However, the use of social media in physiotherapy is still in its infancy, and to date there is a lack of published literature in this field. The School of Physiotherapy Clinic (Dunedin, New Zealand) recently created a Facebook page (Fig. 1) and although several online resources offer guidance as to how to effectively create a Facebook page, ${ }^{24-27}$ no published literature was found to support this process in the context of a physiotherapy clinic. The following provides an outline of the considerations involved in planning, implementing and maintaining a physiotherapy clinic Facebook page.

\section{Planning a Facebook Page}

Before creating a Facebook page, it is important to establish why your physiotherapy clinic wants to start such a page. Some institutions and companies elect not to have a Facebook page as it does not fit with their marketing strategy. ${ }^{28}$ Motivations for having a Facebook page could include increasing the exposure of your clinic, advertising specialist services at your clinic, or to facilitate patient education. From our experience at the School of Physiotherapy, University of Otago, Fig. 4 outlines some of the key issues that need to be considered before creating a Facebook page for a physiotherapy clinic; early consideration of these in advance of creating the page will enable it to have the greatest possible impact.

\section{Implementing a Facebook Page}

Patients (and potential patients) will ultimately base their opinions of a clinic's Facebook page on the content of information posted on the page. Essential items for inclusion are the contact details of the practice, a map showing the location of the clinic, and photographs of the clinic/facilities. Physiotherapy clinics may choose to include information relating to its staff members to acquaint the target audience with their clinical specialities. Potential websites/Facebook links to be incorporated into a clinic's Facebook page could be links to national/international physiotherapy groups (e.g. World Confederation for Physical Therapy ${ }^{29}$ ), disease-specific organisations (e.g. Arthritis New Zealand ${ }^{30}$ ), and patient rights resources. ${ }^{31}$

The Facebook page may also serve as a medium to disseminate news snippets with a local, national, and international flavour. Changes relating to the practice (altered opening hours, special rehabilitation/exercise classes, new staff/equipment etc.) may be shared, as well as features relating to physiotherapy on a national/international level (e.g. informing users about events such as World MS Day ${ }^{32}$ ). Some clinics elect to post self-help strategies for patients on Facebook; ${ }^{33}$ this may include using videos and links from YouTube and can be tailored towards the needs of the caseload seen within each clinic. It is important that any videos or links disseminated through a Facebook page in this manner are clinically accurate, and information should adhere to best-practice clinical guidelines where appropriate. The standard of health information online has been shown to be variable for a variety of medical conditions, ${ }^{34-36}$ and the credibility of the Facebook page will be brought into question if incorrect/inappropriate information is being shared with users. ${ }^{37}$

\section{Maintaining a Facebook Page}

Maintaining a page is essential to ensure that it is up to date: out-of-date information can have a negative effect, and be counter to the marketing strategy which underpinned its development. It is vital to consider time constraints and staff allocation for the upkeep of a Facebook page, and maintaining a page through a designated staff member will provide 


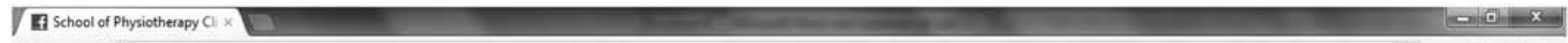

$\leftarrow \rightarrow$ C A https//www.facebookcom/SchoolOfPhysiotherapyClinicsDunedin

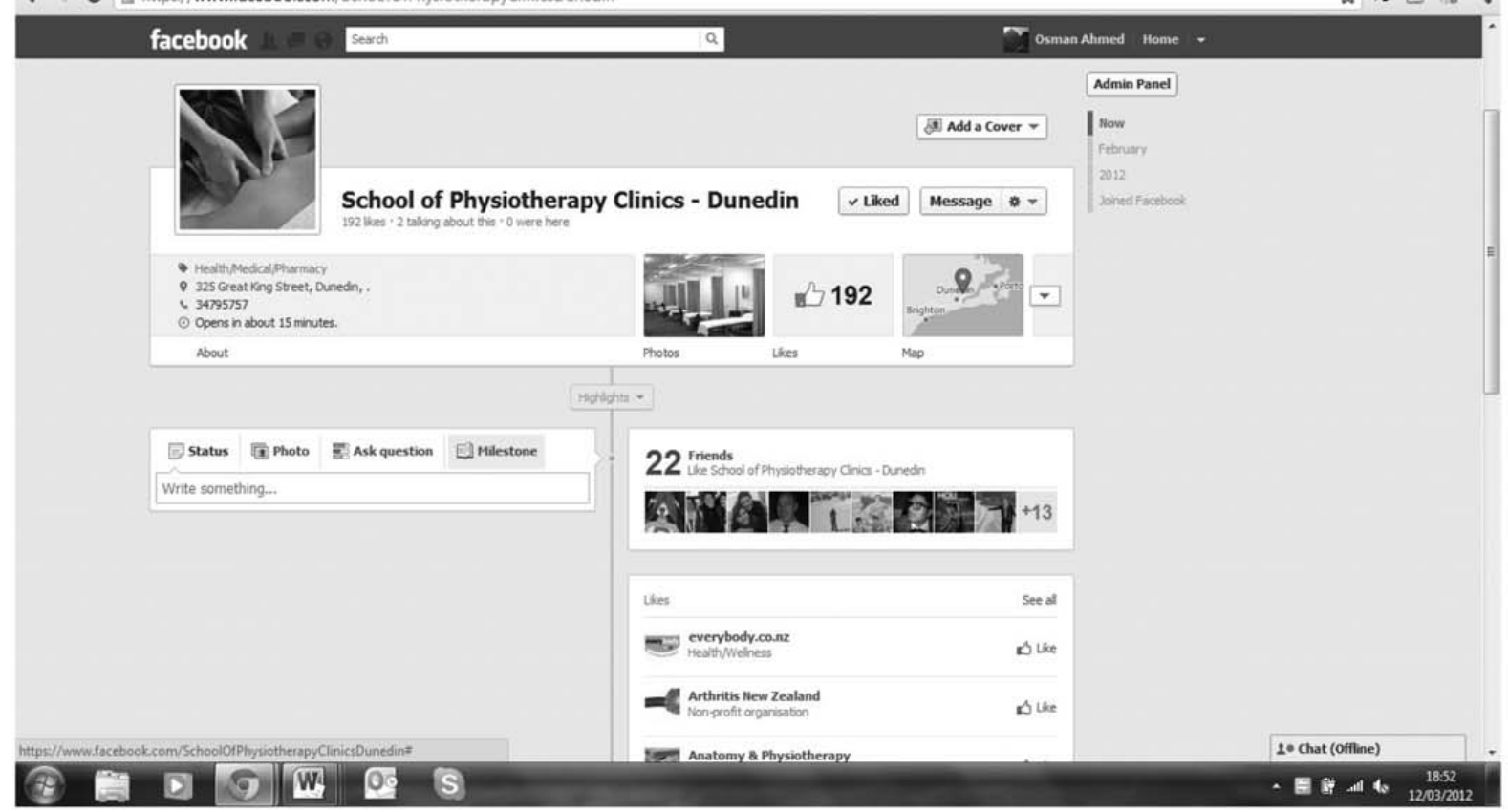

"Wall" The central portion of Facebook page where users can "post" comments: This should be monitored by the individual responsible for administering the page, in order to reply to any comments by Facebook users.

"Post" A note left on the "wall". This can be posted by either the individual responsible for the page, or from any Facebook user who visits the page.

"Like" The option for Facebook users to click on the "like" button to show that they "like" a page, a comment, a link, a video or a photo on Facebook.

"Share" This function allows Facebook users to send content to their friends or to post it on their profile.

Figure 1 Facebook page (School of Physiotherapy Clinics, Dunedin)

continuity. A private clinician who works alone may feel that a Facebook page could become a burden to an already busy working life, whereas larger practices with several members of staff could more readily allocate a staff member for a few hours per week to this task. 


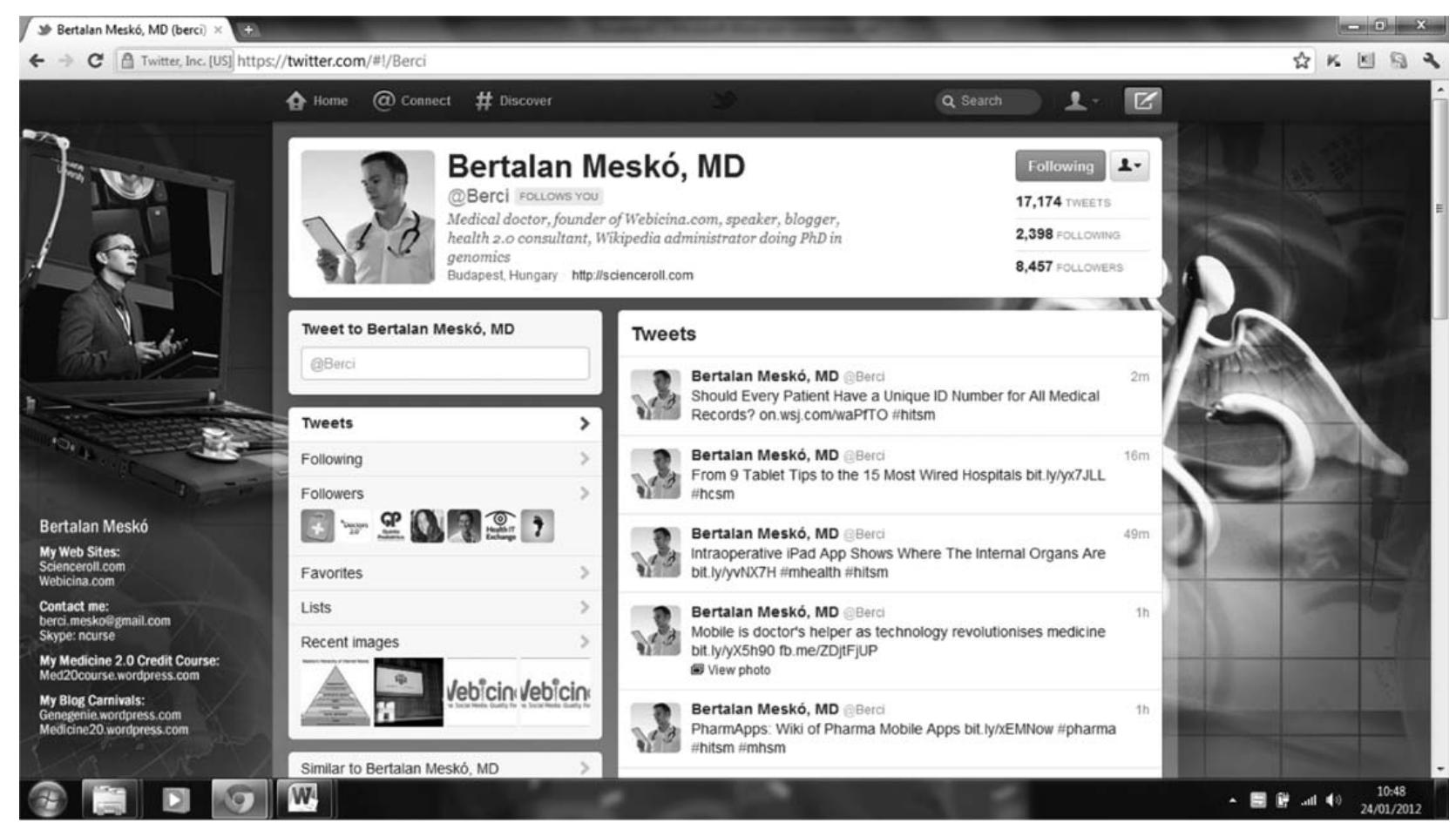

Figure 2 A typical Twitter page

In order to be attractive to the intended audience, to encourage the maximum number of visitors to the page, and to prevent the page from becoming redundant, the Facebook page needs to be regularly updated with new information. Such updates may include details of the services you provide, information regarding physiotherapy techniques and modalities, and images/videos of the clinic. Posting testimonials from patients may be an added advantage in building a positive reputation on the quality of services offered by the clinic. ${ }^{38}$ Queries and comments from users on the Facebook 'wall' should be responded to promptly and fully, in order to build trust with the users that their comments are being noted. When responding to these comments, it is paramount to maintain patient confidentiality at all times. $^{39-41}$

The provision of promotional offers (e.g. discounts on treatment fees) for the users who 'like' the Facebook page may help to increase the number of

ONLINE COLOUR ONLY

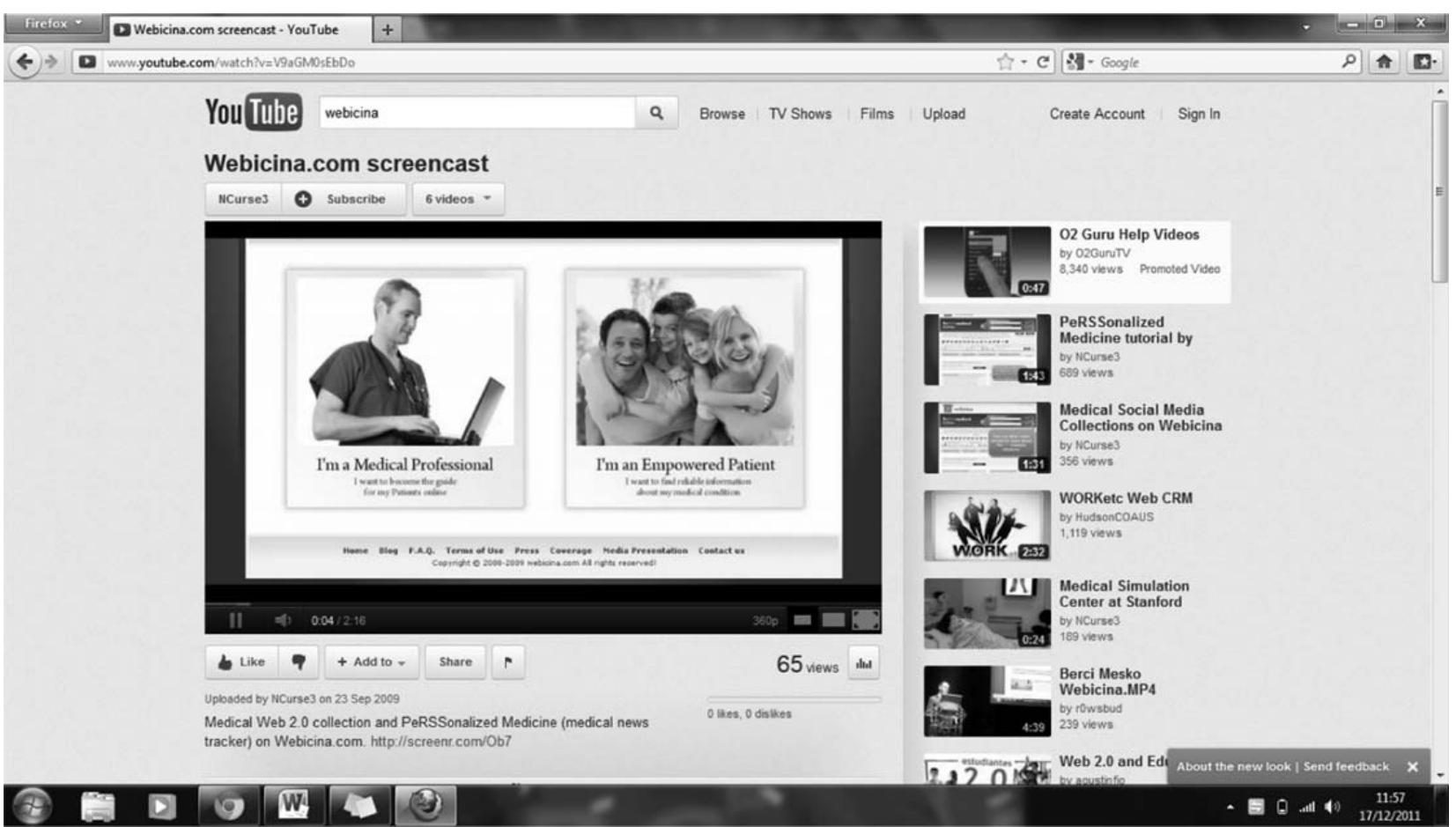

Figure 3 YouTube interface

Physical Therapy Reviews 2012 VOL. 000 NO. 000

Physical Therapy Reviews ptr7316.3d 10/8/12 16:23:49

The Charlesworth Group, Wakefield +44(0)1924 $369598-\operatorname{Rev} 7.51 \mathrm{n} / \mathrm{W}(\mathrm{Jan} 20$ 2003) 


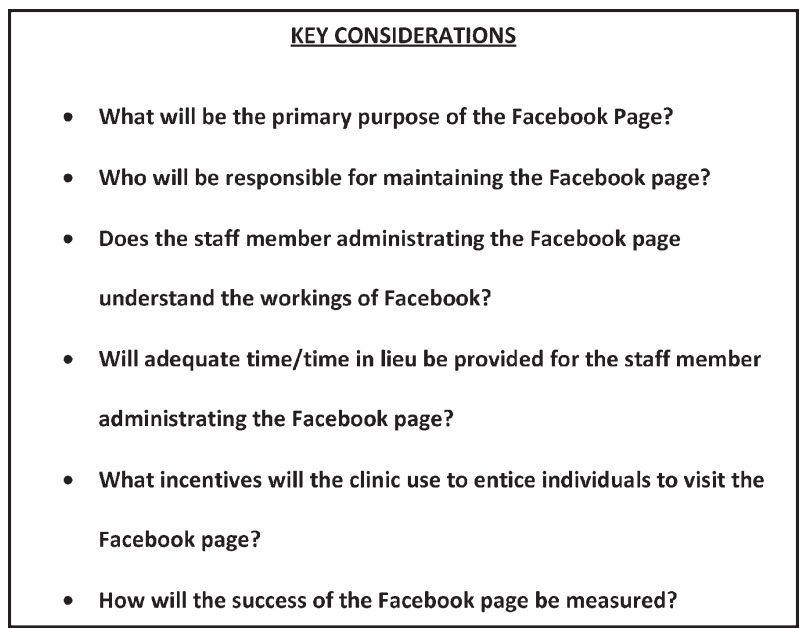

Figure 4 Checklist of considerations for Physiotherapy Clinic Facebook page

members during the initial stages of implementation. ${ }^{42}$ Individuals responsible for maintaining the Facebook page will find it helpful to engage in regular discussion with the physiotherapy clinic staff in order to help respond to queries and comments from the users of the Facebook page. In parallel with this, seeking informal suggestions from current patients regarding the utility, significance, and user friendliness of the Facebook page can help to shape the progression of the page and guide future changes as necessary.

\section{Ethical Considerations}

As well as making sure that the information on a clinic Facebook page is accurate and interesting, it is vital that the page adheres to the regulations and guidelines from the relevant national physiotherapy/ medical organisation. The Chartered Society of Physiotherapy in the United Kingdom ${ }^{43}$ and The Australian Medical Council ${ }^{44}$ have both created working documents to guide their members in terms of using social media professionally. Physiotherapists must respect patient privacy when using social media, just as they would in their day-to-day practice. For example, a physiotherapist in the workplace would never discuss a patient's personal and confidential health status openly in front of a listening audience, and thus it would be equally inappropriate for a physiotherapist to become engaged in a dialogue with a patient about such matters on the clinic's Facebook page as this would be visible by all members. In addition, it would be inappropriate for a clinic to use photographs or videos of patients in the clinic on the Facebook page without prior written consent.

\section{Privacy Settings}

This is an important consideration for any Facebook user. To ensure that anyone can freely access a clinic's Facebook page, it will need to have its privacy settings set to 'public': a 'public' privacy setting means that the clinic's page can be identified by anyone searching Facebook. Facebook users can locate pages on Facebook by using the search tool bar above their 'wall', and can then 'like' a page and/ or write 'posts' on that page (Fig. 1). This can create a marketing opportunity for a clinic, and generate an interactive environment where users can post about topics of interest relating to the clinic.

It is essential to consider the privacy settings of the Facebook accounts for clinic staff and patients, as if the settings of these individuals are 'public' then other Facebook users can view their profiles and any information posted there. A recent study at the University of Otago, New Zealand, found that only $63 \%$ of the 338 doctors who graduated in 2006 and 2007 had activated the privacy settings which restricted the visibility of their Facebook account. ${ }^{40}$ The majority of the doctors who had not activated their privacy settings belonged to 'neutral' groups (e.g. music-related groups) and had 'neutral' photographs (e.g. photographs of themselves working overseas) posted on their profiles. However, $10 \%$ of those who had not activated their privacy settings had photographs of themselves appearing intoxicated, with a minority belonging to groups based on rude/inappropriate humour (e.g. 'Perverts united). ${ }^{40}$ The unimpeded visibility of this information may obviously alter the professional boundaries between patients and staff, ${ }^{40}$ and therefore, it is vital that clinic staff fully understand the privacy settings in Facebook in order to prevent any unprofessional incidents. ${ }^{45}$

\section{Summary and Conclusions}

Social media already plays a large role in the lives of physiotherapists and patients, and as social networking sites continue to grow in terms of number and importance, then it will be a medium that will find increasing use by physiotherapy clinics. Provided that a Facebook page is well-planned, regularly/correctly maintained, and adheres to ethical and professional guidelines, it can be a valuable tool for physiotherapy clinics to better serve their patients.

\section{References}

1 Oxford Dictionaries. Social Media. 2011 [cited 2011 Aug 4]. Available from: http://oxforddictionaries.com/definition/ social + media

2 Pew Internet Institute. $65 \%$ of online adults use social networking sites. 2011 [cited 2011 Nov 11]. Available from: http://pewinternet.org/Reports/2011/Social-Networking-Sites. aspx

3 Facebook. Statistics. 2011 [cited 2011 Nov 11]. Available from: https://www.facebook.com/press/info.php?statistics

4 Pearlman L, Abram C. Facebook for dummies. 3rd ed. Indianapolis (IN): John Wiley \& Sons; 2010.

5 Bender JL, Jimenez-Marroquin MC, Jadad AR. Seeking support on facebook: a content analysis of breast cancer groups. J Med Internet Res. 2011;13(1):e16.

6 Collins T. The little book of Twitter: get Tweetwise! London: Michael O’Mara Books Ltd; 2009. 
7 Tweeternet. What is twitter and why does it keep following me around? 2011 [cited 2011 Nov 12]. Available from: http:// tweeternet.com

8 Pulman A. Twitter as a tool for delivering improved quality of life for people with chronic conditions. J Nurs Healthc Chron Illn. 2009;1(3):245-52.

9 Sullivan SJ, Schneiders AG, Cheang CW, Kitto E, Lee H, Redhead J, et al. 'What's happening?' A content analysis of concussion-related traffic on Twitter. $\mathrm{Br} \mathrm{J}$ Sports Med. 2011;46(4):258-63.

10 Kostkova P, de Quincey E, Jawaheer G. The potential of social networks for early warning and outbreak detection systems: the swine flu Twitter study. Int J Infect Dis. 2010;14:e384-5.

11 Scanfeld D, Scanfeld V, Larson EL. Dissemination of health information through social networks: Twitter and antibiotics. Am J Infect Control. 2010;38(3):182-8.

12 Website Monitoring Blog. YouTube Facts \& Figures (history \& statistics). 2010 [cited 2011 Nov 12]. Available from: http:// www.website-monitoring.com/blog/2010/05/17/youtube-factsand-figures-history-statistics/

13 Alexa: The Web Information Company. YouTube.com's worldwide traffic rank. 2011 [cited 2011 Nov 12]. Available from: http://www.alexa.com/siteinfo/youtube.com

14 Lewis SP, Heath NL, St Denis JM, Noble R. The scope of nonsuicidal self-injury on YouTube. Pediatrics. 2011; 127(3): $552-7$.

15 Lim Fat MJ, Doja A, Barrowman N, Sell E. YouTube videos as a teaching tool and patient resource for infantile spasms. J Child Neurol. 2011;26(7):804-9.

16 Twitter. nhs direct. 2011 [cited 2011 Aug 4]. Available from: http://twitter.com/\#!/nhsdirect

17 The Guardian. NHS Direct considers targeted ads on Facebook and Twitter. 2011 [updated 2011 Jun 17; cited 2011 Aug 3] Available from: http://www.guardian.co.uk/healthcare-network/2011/jun/02/social-media-health-jenny-hyatt-bigwhitewall

18 YouTube. Mayo Clinic Channel. 2011 [cited 2011 Aug 4]. Available from: http://www.youtube.com/user/mayoclinic?blend $=1 \& o b=5$

19 Health Practice Media. New Survey: Patients Choose Hospitals Because of Social Media Presence. 2011 [cited 2011 Nov 11] Available from: http://www.healthpracticemedia.com/?p=673

20 KathieMelocco.net. How physiotherapists can use social media to build influence, educate, collaborate, and grow their business. 2011 [cited 2011 Aug 3]. Available from: http:// kathiemelocco.net.au/2011/05/how-physiotherapists-can-usesocial-media-to-build-influence-educate-collaborate-and-growtheir-business/

21 Giordano C, Giordeno C. Health professions students' use of social media. J Allied Health. 2011;40(2):78-81.

22 Physiotherapy in Motion. Why Social Media Matters For Physiotherapists. 2011 [cited 2011 Nov 11]. Available from: http:// physicaltherapyweb.com/documents/social_media_inmotion.pdf

23 Facebook. Interview questions for junior physios. 2007 [cited 2011 Aug 3]. Available from: http://www.facebook.com/group. php?gid $=3392730320$

24 Alert Presence. Best Hospital Facebook Pages - Individual Hospitals. 2010 [cited 2011 Aug 3]. Available from: http:// www.alertpresence.com/2010/02/23/best-healthcare-facebookpages-individual-hospitals/

25 All Facebook. How To Develop A Facebook Page That Attracts Millions of Fans. 2011 [cited 2011 Aug 3]. Available from: http://www.allfacebook.com/facebook-page-strategy2009-03

26 Focus.com. The Facebook Marketing Toolbox: 100 Tools and Tips to Tap the Facebook Customer Base. 2009 [cited 2011
Aug 3]. Available from: http://www.focus.com/fyi/facebookmarketing-toolbox-100-tools-and-tips-tap-facebook/.

27 Forum One. HealthCare.gov: A Model Facebook Page. 2010 [cited 2011 Aug 3]. Available from: http://www.forumone.com/ blogs/post/healthcaregov-model-facebook-page-0

28 Hive Strategies. Social Media Strategy Blog: Are we Crazy? Lazy? Hazy? Why We Don't Have A Facebook Page. 2010 [cited 2011 Nov 11]. Available from: http://www.hivestrategies. com/2010/10/why-we-do-not-have-a-facebook-page/

29 World Confederation for Physical Therapy. What is WCPT? 2011 [cited 2011 Nov 15]. Available from: http://www.wcpt.orgwhat-is

30 Arthritis New Zealand. Who we are. 2011 [cited 2011 Nov 15]. Available from: http://www.arthritis.org.nz/about-us/who-weare/

31 World Health Organisation. Genomic resource centre: Patients' rights. 2011 [cited 2011 Nov 15]. Available from: www.who.int/ genomics/public/patientrights/en/

32 World MS Day. About World MS Day. 2011 [cited 2011 Nov 15]. Available from: http://worldmsday.org/about-world.msdayl

33 Facebook. Victoria Physiotherapy Clinic. 2011 [cited 2011 Nov 15]. Available from: http://www.facebook.com/Victoria PhysiotherapyClinic

34 Ahmed OH, Sullivan SJ, Schneiders AG, McCrory PR. Concussion information online: evaluation of information quality, content and readability of concussion-related websites. Br J Sports Med. 2012;46(9):675-83.

35 Harland J, Bath P. Assessing the quality of websites providing information on multiple sclerosis: evaluating tools and comparing sites. Health Informatics J. 2007;13(3):207-21.

36 Lewiecki EM, Rudolph LA, Kiebzak GM, Chavez JR, Thorpe BM. Assessment of osteoporosis-website quality. Osteoporos Int. 2006;17(5):741-52.

37 Graham N, Moore P. The dangers of Facebook. Student BMJ. 2008;8(10):354-5.

38 Modern Dental Marketing. Patient Testimonials in Marketing Could Boost Conversion by $100 \%+$. 2001 [cited 2011 Nov 15]. Available from: http://moderndentalmarketing.com/2011/05/ patient-testimonials-in-marketing-could-boost-conversion-by100/

39 Jain SH. Becoming a physician: Practicing medicine in the age of Facebook. N Engl J Med. 2009;361(7):649-51.

40 MacDonald J, Sohn S, Ellis P. Privacy, professionalism and Facebook: a dilemma for young doctors. Med Educ. 2010;44(8):805-13.

41 Mansfield SJ, Morrison SG, Stephens HO, Bonning MA, Wang $\mathrm{SH}$, Withers $\mathrm{AH}$, et al. Social media and the medical profession. Med J Aust. 2011;194(12):642-4.

42 eWay Direct-Blog. Get More Likes By Rewarding People For Liking Your Facebook Page. 2011 [cited 2011 Nov 15]. Available from: http://blog.ewaydirect.com/get-more-likes-byrewarding-people-for-liking-your-facebook-page/

43 Chartered Society of Physiotherapy. Guidance for students using social networking websites, blogs, chat forums, texts and tweets. 2011 [cited 2011 Aug 3]. Available from: http:// www.csp.org.uk/publications/guidance-students-using-socialnetworking-websites-blogschat-forums-texts-tweets

44 Australian Medical Association. Social Media and the Medical Profession. 2010 [cited 2011 Aug 4]. Available from: http:// ama.com.au/node/6231

45 Gusehl JS, Brendel RW, Brendel DH. Medical professionalism in the age of online social networking. J Med Ethics. 2009;35(9):584-6. 


\section{Authors Queries}

Journal: Physical Therapy Reviews

Paper: 7316

Title: Social media for physiotherapy clinics: considerations in creating a Facebook page

Dear Author

During the preparation of your manuscript for publication, the questions listed below have arisen. Please attend to these matters and return this form with your proof. Many thanks for your assistance

\begin{tabular}{|l|l|l|}
\hline $\begin{array}{l}\text { Query } \\
\text { Reference }\end{array}$ & Query & Remarks \\
\hline 1 & $\begin{array}{l}\text { Please confirm the running head } \\
\text { is correct. }\end{array}$ & \\
\hline
\end{tabular}

